\title{
Evaluasi Kapasitas Spillway Bendungan Darma sebagai Salah Satu Dasar dari Aspek Keamanan Bendungan
}

\author{
GERRY PRIMA PUTERA dan YINIARTI EKA KUMALA
}

Jurusan Teknik Sipil, Fakultas Teknik Sipil dan Perencanaan, Institut Teknlogi Nasional Bandung

Email:

\begin{abstract}
ABSTRAK
Kapasitas spillway Bendungan Darma perlu tinjauan kembali mengenai kemampuannya dalam menjaga agar tidak terjadi limpasan karena pada umumnya bendungan yang dibangun dibawah tahun 1980 tidak didesain untuk debit banjir (Q) Probable Maximum Flood (PMF). Dari analisis hidrologi dengan metode Gama 1 untuk penelusuran banjir reservoir didapatkan pada $Q_{1000}$ yaitu $Q_{\text {inflow }}=879,02 \mathrm{~m}^{3} / \mathrm{s}, Q_{\text {outflow }}=574,44 \mathrm{~m}^{3} / \mathrm{s}$ dan $Q_{P M F}$ adalah $Q_{\text {inflow }}=$ $1546,63 \mathrm{~m}^{3} / \mathrm{s}$, Q outflow $=620,74 \mathrm{~m}^{3} / \mathrm{s}$. Berdasarkan hasil perhitungannya didapatkan selisih muka air melimpah dan mercu bendungan pada $Q_{1000}$ adalah $1,83 \mathrm{~m}$ dan pada $Q_{P M F}$ adalah 0,54 $\mathrm{m}$. Saat terjadi banjir $P M F$, bendungan mengalami overtopping karena menurut SNI batas maksimal banjir yang boleh terjadi adalah 0,75 di bawah puncak mercu bendungan.
\end{abstract}

Kata kunci: debit banjir, bendungan, limpasan, Probable Maximum Flood (PMF).

\begin{abstract}
The capacity of the spillway Dam Darma requires review regarding his ability to keep the spillway did not overflow because in general the dam built under the year 1980 is not in design for flood discharge (Q) the Probable Maximum Flood (PMF). Hydrological analysis method of Gama 1 for search flood reservoir obtained on the $Q_{1000}$ are $Q_{\text {inflow }}=879.02 \mathrm{~m}^{3} / \mathrm{s}, Q_{\text {outflow }}=574.44 \mathrm{~m}^{3} / \mathrm{s}$ and $Q_{P M F}$ are $Q_{\text {inflow }}=1546.63 \mathrm{~m}^{3} / \mathrm{s}, Q_{\text {outflow }}=620.74 \mathrm{~m}^{3} / \mathrm{s}$. Based on the results of the calculations are obtained by difference advance water overflow and mercu dam on the $Q_{1000}$ is $1.83 \mathrm{~m}$ and on $Q_{P M F}$ is $0.54 \mathrm{~m}$. At the time of the flood, the dam suffered a PMF overtopping due to flood, according to the maximum limit of the SNI standartmay happen is 0.75 mercu beneath the dam.
\end{abstract}

Keywords: flood discharge, dam, spillway, Probable Maximum Flood (PMF). 


\section{PENDAhUlUAN}

Bendungan Darma (Gambar 1) merupakan salah satu bendungan yang ada di pulau Jawa, berdiri sejak tahun 1961 (Balai Besar Wilayah Sungai Cimanuk-Cisanggarung, 2015). Bendungan Darma ini sudah sangat tua sehingga cenderung akan mengalami limpasan (overtopping) dan keluarnya air lewat lubang-lubang fondasi (piping) sehingga memerlukan bangunan pelimpah yang mampu mengalirkan kelebihan air untuk mencegah kenaikan elevasi muka air banjir pada Bendungan Darma.

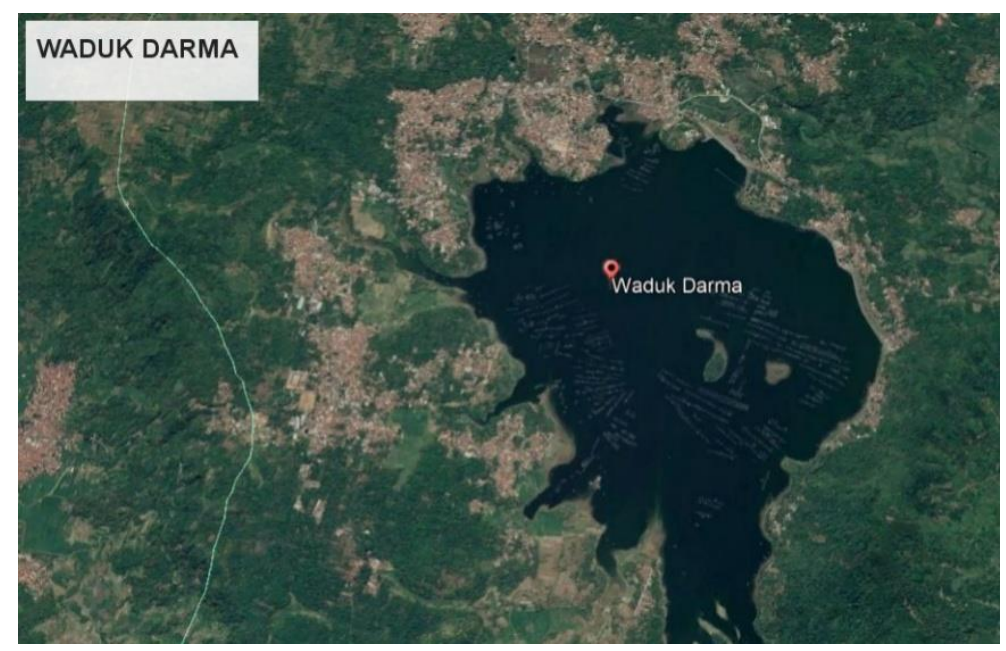

Gambar 1. Foto udara Waduk Darma (Sumber: Google Earth)

Jalan keluarnya sedimen kini mengalami kerusakan akibat jarang dioperasikan selama bertahun-tahun sehingga sedimen yang berada pada Bendungan Darma mengalami penumpukan dalam jumlah besar dan ini menyangkut tentang kapasitas tampungan yang diragukan mampu memenuhi debit rencana dan Probable Maximum Flood (PMF). Apabila volume waduk semakin kecil akibat sedimentasi maka kemungkinan limpasan akibat debit banjir semakin besar. Selain itu perubahan iklim mempengaruhi debit limpasan permukaan yang semakin besar.

Kondisi tersebut diatas memerlukan pengkajian ulang kapasitas pelimpah waduk untuk menghindari limpasan terhadap puncak bendungan. Kaji ulang kapasitas pelimpah waduk ini harus optimal terhadap debit puncak yang paling berbahaya sesuai kriteria tingkat keamanan bendungan sehingga mencukupi sesuai kebutuhan.

\section{METODE PENELITIAN}

Metode yang digunakan adalah orientasi lapangan, pengumpulan data, pengolahan dan analisis data, dan terakhir penyusunan laporan.

a. Orientasi Lapangan

Dalam kegiatan ini dilakukan tinjauan lapangan untuk mengamati lokasi sehingga hal tersebut dapat digunakan sebagai salah satu pertimbangan dalam membuat rencana pelaksanaan.

b. Pengumpulan Data

Kegiatan ini untuk mengumpulkan data sekunder yang dibutuhkan dalam analisis, yaitu:

- Data hujan harian dari Dinas Pekerjaan Umum Kabupaten Kuningan(Kuningan, 2013), BMKG Cirebon, Sumedang, dan Kuningan(Jawa Barat, 2013), Dinas Pertanian 
Kabupaten Kuningan, Dinas Perkebunan dan instansi lain setempat yang mengelola stasiun pencatat curah hujan.

- Hasil perencanaan bangunan pelimpah bendungan.

c. Pengolahan dan Analisis Data

Pengolahan dan analisis data dilaksanakan berdasarkan aspek-aspek yang berkaitan dengan tujuan pekerjaan. Analisis yang dilakukan meliputi:

- Analisis Hidrologi

Analisis dilakukan meliputi analisis curah hujan rencana, debit banjir dengan periode ulang 1.000 tahun $\left(Q_{1000}\right)$ dan Debit PMF $\left(Q_{P M F}\right)$. Selanjutnya hasil analisis digunakan sebagai parameter penelusuran banjir untuk menentukan elevasi muka air banjir dan penentuan kapasitas pelimpah.

- Penelusuran Banjir

Analisis dilakukan untuk menentukan kapasitas pelimpah waduk eksisting dan rekomendasi untuk pelimpah baru dan atau modifikasi pelimpah eksisting.

d. Penyusunan Laporan

Laporan disusun berdasarkan semua hasil setiap tahap pelaksanaan pekerjaan yang memuat tentang deskripsi, cara pelaksanaan pekerjaan yang dilakukan, hasil analisis, kesimpulan dan rekomendasi. Laporan disertai lampiran yang dibutuhkan.

\section{ANALISIS DAN PEMBAHASAN}

\subsection{Pengolahan Data Curah Hujan}

Berdasarkan perhitungan curah hujan harian dari tahun 2001-2013 (Tabel 1) didapatkan nilai curah hujan rata-rata 105,269 mm dan standar deviasi 22,641 mm.

Tabel 1. Data Curah Hujan Harian Maksimum Daerah Tangkapan Air Waduk Darma

\begin{tabular}{ccc}
\hline No & Tahun & Hujan Asli [mm] \\
\hline 1 & 2001 & 116 \\
\hline 2 & 2002 & 129 \\
\hline 3 & 2003 & 154 \\
\hline 4 & 2004 & 97 \\
\hline 5 & 2005 & 102 \\
\hline 6 & 2006 & 133 \\
\hline 7 & 2007 & 70 \\
\hline 8 & 2008 & 81 \\
\hline 9 & 2009 & 98 \\
\hline 10 & 2010 & 96,5 \\
\hline 11 & 2011 & 90 \\
\hline 12 & 2012 & 98 \\
\hline 13 & 2013 & 104
\end{tabular}

\subsection{Perhitungan Curah Hujan Rancangan}

Terdapat 5 metode untuk menghitung curah hujan harian, yaitu:

1. Analisis Frekuensi Normal.

2. Analisis Log Normal 2 Parameter.

3. Analisis Log Normal 3 Parameter.

4. Analisis Gumbel.

5. Analisis Frekuensi Pearson III. 
Dari hasil perhitungan curah hujan rancangan dengan menggunakan 5 metode tersebut, didapatkan hasil pada Tabel $\mathbf{2}$ sebagai berikut:

Tabel 2. Curah Hujan Rancangan Daerah Tangkapan Air Waduk Darma

\begin{tabular}{ccccccc}
\hline $\begin{array}{c}\text { Kala } \\
\text { Ulang } \\
\text { [Tahun] }\end{array}$ & $\begin{array}{c}\text { Analisis } \\
\text { Frekuensi } \\
\text { Normal }\end{array}$ & $\begin{array}{c}\text { Analisis } \\
\text { Log Normal } \\
\text { 2 Parameter }\end{array}$ & $\begin{array}{c}\text { Analisis } \\
\text { Log Normal } \\
\text { 2 Parameter }\end{array}$ & $\begin{array}{c}\text { Analisis } \\
\text { Gumbel I }\end{array}$ & $\begin{array}{c}\text { Analisis Log } \\
\text { Pearson III }\end{array}$ & $\begin{array}{c}\text { Analisis Log } \\
\text { Pearson III }\end{array}$ \\
\hline 2 & 105,3 & 103,1 & 102,9 & 101,5 & 102,5 & 100,5 \\
\hline 5 & 124,3 & 123,1 & 123,1 & 121,6 & 123,0 & 121,6 \\
\hline 10 & 134,3 & 135,0 & 135,2 & 134,8 & 135,4 & 136,4 \\
\hline 20 & 142,5 & 145,7 & 146,0 & 147,5 & 146,6 & 151,4 \\
\hline 25 & 144,9 & 149,0 & 149,3 & 151,5 & 150,0 & 156,3 \\
\hline 50 & 151,8 & 158,8 & 159,2 & 164,0 & 160,3 & 171,8 \\
\hline 100 & 157,9 & 168,2 & 168,7 & 176,3 & 170,0 & 188,1 \\
\hline 200 & 163,6 & 177,2 & 177,8 & 188,6 & 179,4 & 205,2 \\
\hline 500 & 170,4 & 188,8 & 189,6 & 204,8 & 191,4 & 229,4 \\
\hline 1000 & 175,2 & 197,4 & 198,3 & 217,0 & 200,2 & 249,0 \\
\hline
\end{tabular}

\subsection{Debit BanjirRencana}

Perhitungan banjir rencana dapat dihitung dengan beberapa metode. Perhitungan debit banjir rencana daerah tangkapan air khususnya pada bendungan di Indonesia yang umum digunakan yaitu Metode Gama 1, Metode Nakayasu, dan Metode Snyder Aleksejev.

Berdasarkan Tabel 3 debit banjir rancangan daerah tangkapan air waduk Darma disimpulkan bahwa metode yang digunakan untuk analisis selanjutnya adalah debit banjir rancangan Gama 1 karena metode Gama 1 memiliki debit banjir terbesar dibandingkan dengan metode yang lain.

Tabel 3. Debit Banjir Rancangan Daerah Tangkapan Air Waduk Darma

\begin{tabular}{|c|c|c|c|}
\hline \multirow{3}{*}{$\begin{array}{c}\text { Peride } \\
\text { Ulang } \\
\text { [Tahun] }\end{array}$} & \multicolumn{3}{|c|}{ Metode } \\
\hline & Gama 1 & $\begin{array}{c}\text { Snyder } \\
\text { Aleksejev }\end{array}$ & Nakayasu \\
\hline & \multicolumn{3}{|c|}{$\left[\mathrm{m}^{3} / \mathrm{s}\right]$} \\
\hline 2 & 197,0 & 290,2 & 230,9 \\
\hline 5 & 521,5 & 313,8 & 243,7 \\
\hline 10 & 458,2 & 321,6 & 250,4 \\
\hline 20 & 596,9 & 336,3 & 255,9 \\
\hline 25 & 606,8 & 339,2 & 257,5 \\
\hline 50 & 635,3 & 347,7 & 262,2 \\
\hline 100 & 660,9 & 355,4 & 266,3 \\
\hline 200 & 684,3 & 362,4 & 270,1 \\
\hline 500 & 712,6 & 370,8 & 274,7 \\
\hline 1000 & 732,5 & 376,8 & 278,0 \\
\hline PMP & 1546,6 & 619,7 & 410,2 \\
\hline
\end{tabular}

\subsection{Kapasitas Waduk}

Topografi pengukuran kapasitas waduk Darma ((Persero), 1991) dengan hasil sebagaimana Tabel 4 dan dideskripsikan pada Gambar 2 adalah sbb.: 
Tabel 1. Kapasitas Waduk Darma

\begin{tabular}{|c|c|c|c|c|c|}
\hline $\begin{array}{c}\text { Elevasi } \\
\text { [El.m] }\end{array}$ & $\begin{array}{c}\text { Volume } \\
{\left[\mathrm{m}^{3}\right]}\end{array}$ & $\begin{array}{c}\text { Area } \\
\text { ha }\end{array}$ & $\begin{array}{c}\text { Elevasi } \\
\text { [El.m] }\end{array}$ & $\begin{array}{c}\text { Volume } \\
{\left[\mathrm{m}^{3}\right]}\end{array}$ & $\begin{array}{l}\text { Area } \\
\text { [ha] }\end{array}$ \\
\hline 697.00 & 47.00 & 200.00 & 706.50 & $13,392,860.00$ & $2,710,530.00$ \\
\hline 697.50 & $75,379.00$ & $189,190.00$ & 707.00 & $14,800,017.00$ & $2,850,375.00$ \\
\hline 698.00 & $123,740.00$ & $354,628.00$ & 707.50 & $16,266,670.00$ & $2,947,370.00$ \\
\hline 698.50 & $277,780.00$ & $526,320.00$ & 708.00 & $17,764,095.00$ & $3,079,250.00$ \\
\hline 699.00 & $644,973.00$ & $708,000.00$ & 708.50 & $19,200,000.00$ & $3,210,530.00$ \\
\hline 699.50 & $1,111,110.00$ & $842,110.00$ & 709.00 & $20,978,569.00$ & $3,351,625.00$ \\
\hline 700.00 & $1,501,405.00$ & $1,014,000.00$ & 709.50 & $22,606,380.00$ & $3,421,050.00$ \\
\hline 700.50 & $2,083,330.00$ & $1,105,260.00$ & 710.00 & $24,407,588.00$ & $3,507,000.00$ \\
\hline 701.00 & $2,613,481.00$ & $1,213,125.00$ & 710.50 & $26,133,330.00$ & $3,617,160.00$ \\
\hline 701.50 & $3,333,333.00$ & $1,342,110.00$ & 711.00 & $28,000,000.00$ & $3,680,250.00$ \\
\hline 702.00 & $3,953,595.00$ & $1,471,250.00$ & 711.50 & $29,732,140.00$ & $3,762,380.00$ \\
\hline 702.50 & $4,722,220.00$ & $1,578,950.00$ & 712.00 & $31,761,328.00$ & $3,841,250.00$ \\
\hline 703.00 & $5,536,012.00$ & $1,696,250.00$ & 712.50 & $33,704,752.00$ & $3,932,620.00$ \\
\hline 703.50 & $6,351,350.00$ & $1,842,110.00$ & 713.00 & $35,693,599.00$ & $4,024,000.00$ \\
\hline 704.00 & $7,385,947.00$ & $2,008,000.00$ & 713.50 & $37,866,670.00$ & $4,116,180.00$ \\
\hline 704.50 & $8,513,510.00$ & $2,184,210.00$ & 714.00 & $39,802,554.00$ & $4,194,500.00$ \\
\hline 705.00 & $9,571,194.00$ & $2,367,425.00$ & 714.50 & $42,071,010.00$ & $4,288,240.00$ \\
\hline 705.50 & $10,714,290.00$ & $2,500,000.00$ & 715.00 & $44,082,269.00$ & $4,365,500.00$ \\
\hline 706.00 & $12,064,725.00$ & $2,621,800.00$ & & & \\
\hline
\end{tabular}

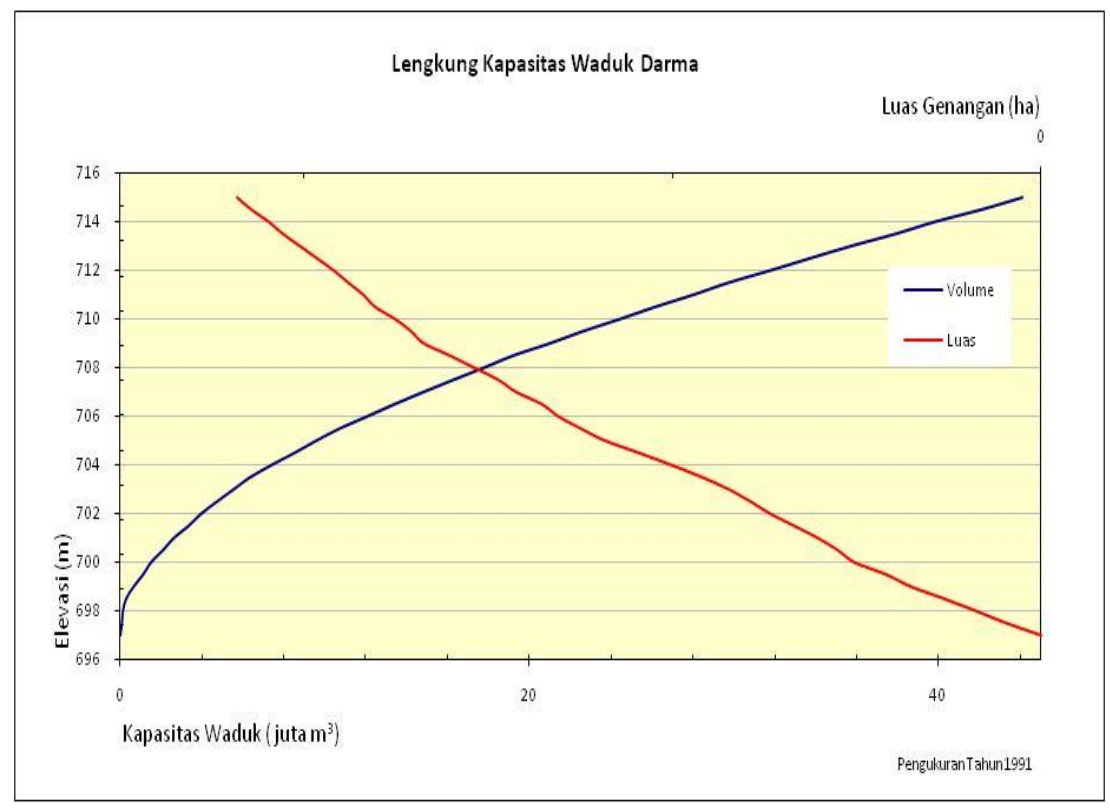

Gambar 1. Lengkung Kapasitas Waduk Darma

\subsection{Penelusuran Banjir}

Data desain pelimpah waduk Darma adalah sebagai berikut :
a. Banjir desain
: $132,40 \mathrm{~m}^{3} / \mathrm{s}$.
b. Debit banjir periode ulang
1.000 tahun.
c. Kapasitas
: $125,00 \mathrm{~m}^{3} / \mathrm{s}$
d. Elevasi mercu
: $+712,50 \mathrm{~m}$.

Hasil analisis penelusuran banjir pada waduk Darma menggunakan parameter dan hasil sebagai berikut: 

a. Debit banjir periode ulang : 1.000 tahun
e. Debit aliran masuk : $879,02 \mathrm{~m}^{3} / \mathrm{s}$.
f. Debit aliran keluar : $574,44 \mathrm{~m}^{3} / \mathrm{s}$.
b. Elevasi muka air melimpah : $+713,17 \mathrm{~m}$.
c. Elevasi mercu bendungan : $+715,00 \mathrm{~m}$.
Debit banjir periode ulang : PMF.
g. Debit aliran masuk : $1.546,63 \mathrm{~m}^{3} / \mathrm{s}$.
h. Debit aliran keluar : $620,74 \mathrm{~m}^{3} / \mathrm{s}$.
a. Elevasi muka air melimpah : $+714,46 \mathrm{~m}$
b. Elevasi mercu bendungan : $+715,00 \mathrm{~m}$

Berdasarkan hasil analisis sebagaimana dideskripsikan pada Gambar 2 dan Gambar 3, didapatkan selisih muka air melimpah dan mercu bendungan pada $Q_{1000}$ adalah $1,83 \mathrm{~m}$ dan pada $Q_{\text {PMF }}$ adalah 0,54 m sehingga hal ini menunjukkan bahwa bendungan Darma masih aman terhadap kemungkinan overtopping. Saat terjadi banjir PMF bendungan mengalami overtopping karena menurut SNI batas maksimal banjir yang boleh terjadi adalah 0,75 di bawah puncak mercu bendungan.

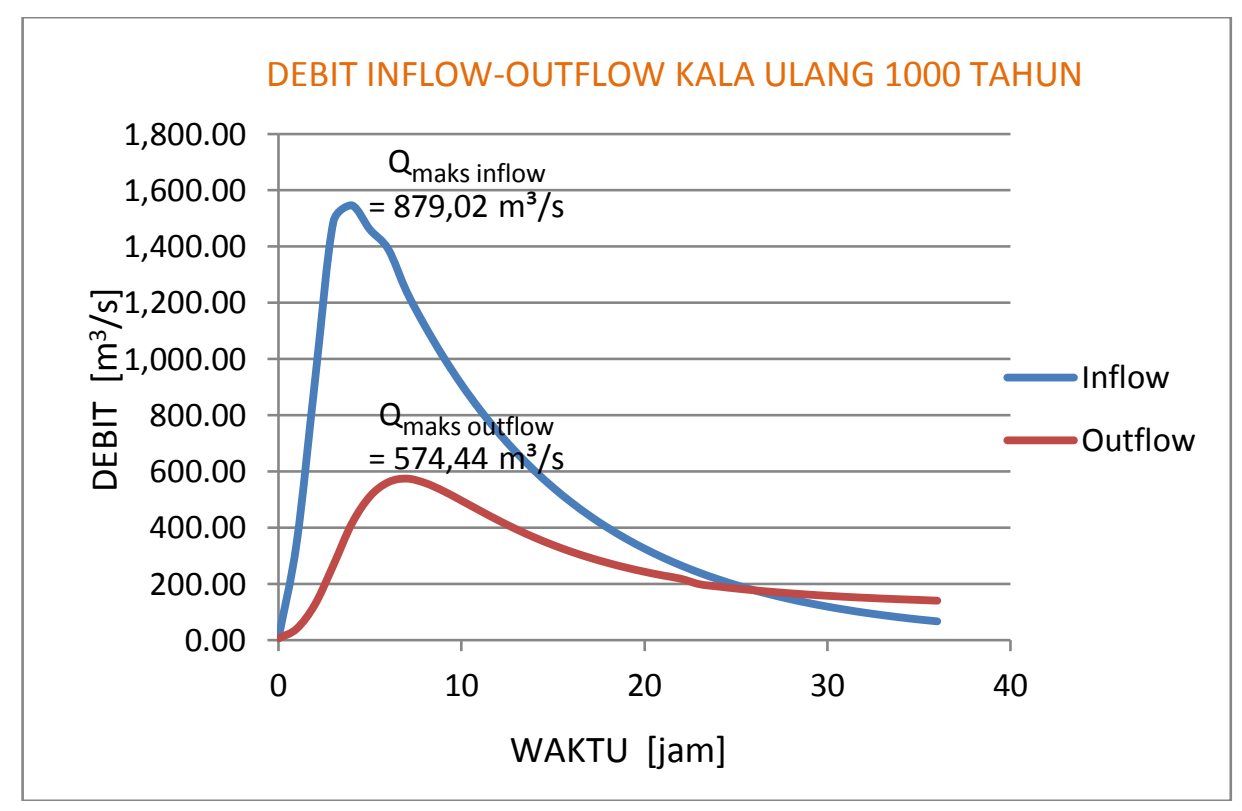

Gambar 3. Penelusuran banjir Waduk Darma dengan $Q_{1000}$ 


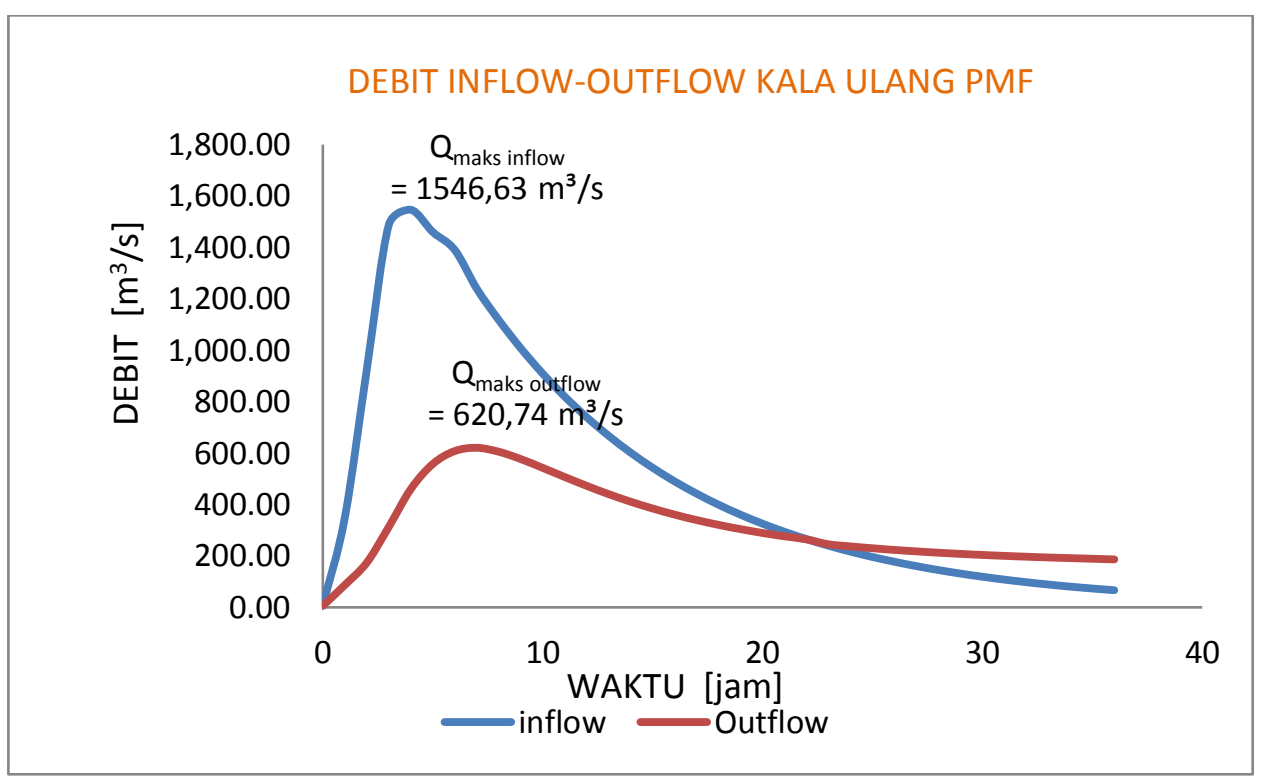

Gambar 4. Penelusuran banjir Waduk Darma dengan $Q_{\mathrm{PMF}}$

\section{KESIMPULAN DAN SARAN}

Kesimpulan:

1. Debit banjir yang terbesar diproleh berdasarkan hasil analisis hidrologi menggunakan metode Gama I.

2. Berdasarkan analisis debit banjir dan penelusuran banjir waduk didapatkan bahwa nilai $Q_{1000}$ tahun sebesar $879,02 \mathrm{~m}^{3} / \mathrm{s}$ dan elevasi muka air banjir hasil penelusuran waduk adalah $+713,17 \mathrm{~m}$ dengan elevasi puncak mercu bendungan adalah $+715,00 \mathrm{~m}$. Pada analisis debit banjir PMF didapatkan nilai debit banjir sebesar $Q_{\text {PMF }} 1.546,63 \mathrm{~m}^{3} / \mathrm{s}$ dan elevasi muka air banjir sebesar $714,46 \mathrm{~m}^{3} / \mathrm{s}$. Berdasarkan analisis tersebut, bendungan aman terhadap kemungkinan overtopping, selisih muka air $Q_{1000}$ terhadap mercu bendungan sebesar $1,83 \mathrm{~m}$ dan selisih $Q_{\text {PMF }}$ sebesar 0,54 m. Saat terjadi banjir PMF bendungan mengalami overtopping karena menurut SNI batas maksimal banjir yang boleh terjadi adalah 0,75 di bawah puncak mercu bendungan.

\section{Saran:}

1. Untuk mengantisipasi terjadinya overtopping pada bendungan sebaiknya digunakan parapet.

2. Untuk mendapatkan nilai debit yang lebih akurat sebaiknya gunakan data AWLR (Automatic Water Level Recorder) karena bendungan Darma telah beroperasi dari tahun 1970-an sehingga memungkinkan untuk mendapatkan data AWLR. Data yang digunakan saat ini berdasarkan data curah hujan sehingga ada kemungkinan debit banjir yang ada lebih kecil atau bahkan bisa lebih besar sehingga memungkinkan bendungan mengalami limpasan.

3. Dalam analisis tidak dimasukkan debit kebutuhan untuk PLTA, irigasi, keperluan rumah tangga, dan lain-lain sehingga bila hal tersebut bisa dimasukkan dalam perhitungan analisis hasilnya yang di peroleh akan lebih akurat.

\section{DAFTAR RUJUKAN}

(Persero), P. I. (1991). Topografi Pengukuran Kapasitas Waduk Darma. Jakarta: 
Balai Besar Wilayah Sungai Cimanuk-Cisanggarung, D. J. (2015). Permasalahan Kelembagaan Pemanfaatan Waduk Darma Kabupaten Kuningan Jawa Barat. Jurnal Wilayah dan Lingkungan, 3 (

Jawa Barat, B. (2013). Data Curah Hujan Harian. Cirebon:

Kuningan, D. P. (2013). Data Curah Hujan. Kuningan: 